\title{
EVOLUTION OF A SYLLABUS: TEACHING SOCIAL BUSINESS
}

\author{
William Frech, Ramapo College of New Jersey, Mahwah, New Jersey, USA
}

\author{
dx.doi.org/10.18374/JIBE-13-2.4
}

\begin{abstract}
This paper is an examination of some of the variables in the dynamics of income inequality. In constructing a teaching syllabus for an honors class on social business, the author developed themes from three noted economists, Peruvian, Bangladesh and American to support the concepts of social business. The syllabus is included as an appendix.
\end{abstract}

Keywords: Social Business, Income Inequality, Hernando de Soto, Mohammad Yunus, Joseph Stiglitz 